\title{
The Development of Advanced Optical Fibers for Long-Wave Infrared Transmission
}

\author{
Pierre Lucas $^{1}{ }^{*}$, Catherine Boussard-Pledel ${ }^{2}$, Allison Wilhelm ${ }^{1,2}$, Sylvain Danto ${ }^{3}$, \\ Xiang-Hua Zhang ${ }^{2}$, Patrick Houizot ${ }^{4}$, Sebastien Maurugeon ${ }^{2}$, Clément Conseil ${ }^{2}$ and \\ Bruno Bureau ${ }^{2}$
}

1 Department of Materials Science and Engineering, University of Arizona, Tucson, AZ 85712, USA; E-Mail: awilhelm@gmail.com

2 Laboratoire des Verres et Ceramiques, UMR-CNRS 6226, Universite de Rennes 1, 35042 Rennes, France; E-Mails: catherine.boussard@univ-rennes1.fr (C.B-P); xzhang@univ-rennes1.fr (X-H.Z.); smauruge@gmail.com (S.M.); clement.conseil@univ-lemans.fr (C.C.);

bruno.bureau@univ-rennes1.fr (B.B)

3 ICMCB/CNRS University of Bordeaux, 87 Avenue du Dr. Schweitzer, 33608 Pessac, France; E-Mail: sylvain.danto@u-bordeaux1.fr

4 LARMAUR ERL CNRS 6274, Université de Rennes 1, Campus de Beaulieu, 35042 Rennes Cedex, France; E-Mail: patrick.houizot@univ-rennes1.fr

* Author to whom correspondence should be addressed; E-Mail: pierre @u.arizona.edu;

Tel.: +1-520-322-2311.

Received: 15 November 2013; in revised form: 10 December 2013 / Accepted: 11 December 2013 / Published: 17 December 2013

\begin{abstract}
Long-wave infrared fibers are used in an increasing number of applications ranging from thermal imaging to bio-sensing. However, the design of optical fiber with low-loss in the far-infrared requires a combination of properties including good rheological characteristics for fiber drawing and low phonon energy for wide optical transparency, which are often mutually exclusive and can only be achieved through fine materials engineering. This paper presents strategies for obtaining low loss fibers in the far-infrared based on telluride glasses. The composition of the glasses is systematically investigated to obtained fibers with minimal losses. The fiber attenuation is shown to depend strongly on extrinsic impurity but also on intrinsic charge carrier populations in these low band-gap amorphous semiconductor materials.
\end{abstract}

Keywords: infrared fibers; chalcogenide glass; telluride glass; long-wave infrared 


\section{Introduction}

Glass fibers with optical windows extending into the infrared domain are in demand for an increasing number of applications ranging from bio-medical sensing to defense. In particular, infrared fibers with transmission down to the long-wave infrared up to 16 microns are of special interest for applications such as micro-organism detection [1-3], environmental monitoring [4-6], medical diagnostic [7,8], thermal imaging through fiber bundles [9], laser surgery delivery at 10.6 microns [10], $\mathrm{CO}_{2}$ gas monitoring for space exploration [11-13] as well as optical communication in the second atmospheric window at 8-12 microns.

Chalcogenide glasses are composed of heavy elements such as S, Se and Te that result in low phonon energies and consequently push the optical cut-off far into the infrared up to 25 microns $[11,13,14]$. In addition, these materials have excellent resistance against crystallization and can be molded or drawn into complex shapes to produce optical elements such as fibers and lenses [15]. Overall, chalcogenide glasses are the only class of amorphous materials that combine far infrared transparency and good rheological properties. Among chalcogenide glasses, sulfur-based compositions have the shorter optical cut-off around 10 microns due to their lighter elemental mass [16]. Selenide-based glasses have a longer transmission up to 16 microns but for far-infrared applications tellurides are the optimal choice with transmissions up to 25 microns [11]. In the fiber form, residual absorptions on the edges of the optical window play an important role, which significantly reduces the effective width of the transparency domain for transmission over long distances. Nevertheless, high purity telluride fibers permit effective low-loss transmission past 10 microns [14,17-21].

The fine balance between far-infrared optical cut-off, good rheological properties and thermal stability can be tuned through appropriate compositional engineering of the glass matrix. While elemental tellurium is not intrinsically a glass-forming material, it can be combined with neighboring elements to improve its resistance to crystallization while retaining its wide optical transparency [17]. Initial attempts at improving telluride glass properties involved the so-called "TeX" fiber where large amounts of heavy, monovalent halide elements were introduced in the glass compositions [22-24]. However, the resulting low structural connectivity leads to low glass transition temperatures $T_{g}$ which limited their practical applications. In this paper, we review some recent materials engineering approaches aimed at optimizing the width of the optical window and the rheological properties of telluride glasses for the fabrication of long wave transmitting fibers. The attenuation of telluride fibers with optimized compositions is presented.

\section{Experimental Section}

\subsection{Material Preparation}

Telluride glasses are synthesized from high purity $(6 \mathrm{~N})$ elements introduced in silica ampoules under high vacuum $\left(\sim 10^{-5}\right.$ Torr). All materials are initially stored in controlled atmosphere and tellurium is first etched with hydrobromic acid to remove surface oxide before introduction in the reaction tube. In order to further remove any oxide impurity, the components are mixed with an oxygen getter such as metallic aluminum. After reaction, the resulting glass is distilled and further homogenized by heating up to $750{ }^{\circ} \mathrm{C}$ at $5{ }^{\circ} \mathrm{C} / \mathrm{min}$ in a rocking furnace and held at that temperature for 
$12 \mathrm{~h}$. For glass containing gallium, the distillation step is not possible due to the extremely low vapor pressure of gallium. In this case, as received pure elements are used. After homogenization the glass melts are cooled to $600{ }^{\circ} \mathrm{C}$ and the ampoules are held vertically before quenching in water. The glasses are then annealed near $T_{g}$ for $2 \mathrm{~h}$ to remove internal stress and slowly cooled to room temperature. The resulting glasses are inspected by X-Ray diffraction to ensure of their amorphous nature. The glass transition temperature $T_{g}$ and crystallization temperature $T_{x}$ are characterized by differential scanning calorimetry (DSC) to estimate the materials stability against crystallization. DSC measurements are performed using $\sim 10 \mathrm{mg}$ of glass sample introduced in a sealed aluminum pan and heated at a rate of $10{ }^{\circ} \mathrm{C} / \mathrm{min}$. The $T_{g}$ is estimated as the onset of the endothermic heat capacity jump while the $T_{x}$ is estimated as the onset of the exothermic crystallization peak. The rods produced this way are used as preforms for fiber drawing.

\subsection{Fiber Preparation}

Single-index fibers are produced from $7 \mathrm{~mm}$ diameter preforms using a custom-built fiber drawing tower with a narrow ring heater. The preforms are heated above $T_{g}$ under a flow of helium and drawn under controlled tension to adjust the diameter to fixed value ranging between 100-300 microns. The fibers are then directly rolled onto polystyrene cylinders.

The optical properties of the resulting fibers are characterized using an FTIR spectrometer Tensor 27 from Bruker equipped with a fiber coupling attachment using gold coated concave mirrors and an external Mercury-Cadmium-Telluride (MCT) detector. The fiber attenuations are measured using the cut-back method over the full infrared range. The typical fiber diameter used for loss measurement was $\sim 250$ microns

\section{Results and Discussion}

In contrast to selenium, tellurium does not vitrify in the elemental form but instead crystallizes into a semimetallic solid with hexagonal structure $[25,26]$. The metallic character of tellurium results from significant p-orbital overlap [27] which promotes the formation of periodic helicoidal chains and prevents the structural disorder required for glass formation. The addition of higher valence elements such as germanium or gallium is therefore necessary to cross-link the structure into a random covalent network and mitigate the metallic character.

\subsection{Tellurium-Germanium-Gallium Fibers}

The addition of gallium and germanium into tellurium is indeed shown to markedly improve the glass-formation tendency [13]. The resulting structure is composed of interconnected $\mathrm{GaTe}_{4}$ and $\mathrm{GeTe}_{4}$ tetrahedra which form a flexible three dimensional network conducive to glass-formation [28]. These glasses have relatively high $T_{g}$ in the range $135-185{ }^{\circ} \mathrm{C}$ and show good resistance against crystallization with values of $\Delta T=T_{x}-T_{g}$ as high as $113{ }^{\circ} \mathrm{C}$ for the $\mathrm{Ge}_{15} \mathrm{Ga}_{10} \mathrm{Te}_{75}$ composition. These values of $\Delta T$ are notably larger than that of gallium free $\mathrm{GeTe}_{\mathrm{x}}$ glasses which exhibit values near $\Delta T \sim 70{ }^{\circ} \mathrm{C}$. This demonstrates that gallium atoms play a major role in the stabilization of the amorphous structure of these materials. 
The range of $\Delta T$ of Ge-Ga-Te is sufficient for the production of glass fiber without formation of crystallite which can induce significant scattering and be detrimental for optical attenuations. The production of single index optical fibers was therefore attempted using the glass of composition $\mathrm{Ge}_{15} \mathrm{Ga}_{10} \mathrm{Te}_{75}$ with the largest $\Delta T$ in the Ge-Ga-Te system. Figure 1 shows the attenuation curve measured by the cut-back method on a small section of fiber. The attenuation is relatively high with a minimum of $40 \mathrm{~dB} / \mathrm{m}$ near $12-13$ microns. The source of these fairly high losses is most likely due to a combination of intrinsic and extrinsic factors. The intrinsic losses are likely the results of large background absorptions due to the presence of free charge carriers. Indeed it has been demonstrated that low band-gap glasses contain a large population of thermally excited charge carriers which induces optical absorption that increase exponentially with temperature [29]. Very low band-gap energies which lead to high electrical conductivity are therefore detrimental to optical properties. Extrinsic losses on the other hand are likely due to impurity absorption resulting from the fact that gallium containing glasses cannot be purified in-situ by distillation. The presence of oxygen, water or carbon impurities result in significant losses within the optical window, as is well known in chalcogenide fibers [30]. These two sources of optical losses impose severe limitation on the potential of Ge-Ga-Te fibers for low-loss glass fibers hence novel strategies have been investigated to obtain glasses with improved transparency.

Figure 1. Attenuation curve of a $\mathrm{Ge}_{15} \mathrm{Ga}_{10} \mathrm{Te}_{75}$ glass fiber showing minimum loss around 12-13 microns.

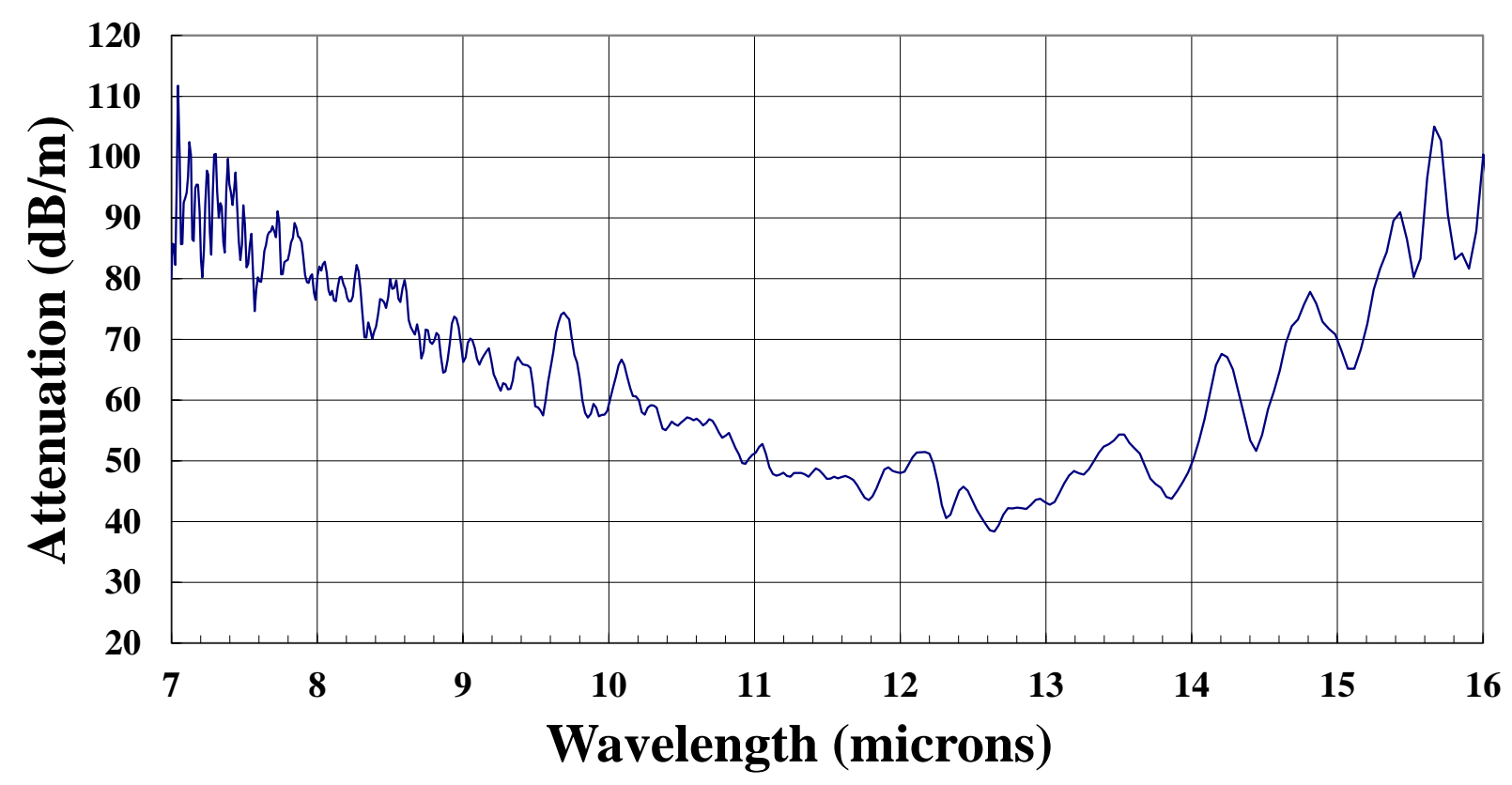

\subsection{Tellurium Germanium Iodine Fibers}

In order to mitigate the sources of optical losses associated with impurities, gallium-free glasses that can undergo in-situ distillation were developed. As mentioned previously, one of the most beneficial functions of gallium was to stabilize the amorphous network against crystallization relative to pure $\mathrm{GeTe}_{\mathrm{x}}$ glasses. The removal of gallium must therefore be compensated by addition of other elements that can modify and reduce the rigidity of the Ge-Te network and suppress crystallization. The addition 
of monovalent iodine can serve such a purpose by reducing the structural connectivity. Indeed it was shown that the iodine selectively bonds to the germanium atoms thereby producing larger ring structure in the amorphous network [31]. This added structural flexibility effectively suppresses crystallization and $\Delta T$ values up to $124^{\circ} \mathrm{C}$ can be obtained with addition of only a few percent of iodine [11]. The electronegative nature of iodine may also help widen the band-gap [32] and in turn lower charge carrier absorptions.

Another major advantage of iodine is that it has the same mass as tellurium and consequently does not alter the phonon energy negatively by reducing the cut-off window. These glasses are therefore good candidates for far infrared applications and single index fibers were produced from a $\mathrm{Ge}_{19.8} \mathrm{Te}_{79.2} \mathrm{I}_{1}$ glass preform with a $\Delta T=110{ }^{\circ} \mathrm{C}$. The optical attenuations for this fiber are presented in Figure 2. The minimum losses reach $20 \mathrm{~dB} / \mathrm{m}$ which constitutes a significant reduction relative to that of the $\mathrm{Ge}_{15} \mathrm{Ga}_{10} \mathrm{Te}_{75}$ glass. This is likely the result of lower impurity content.

Figure 2. Attenuation curve of a $\mathrm{Ge}_{19.8} \mathrm{Te}_{79.2} \mathrm{I}_{1}$ glass fiber showing minimum loss around 12 microns.

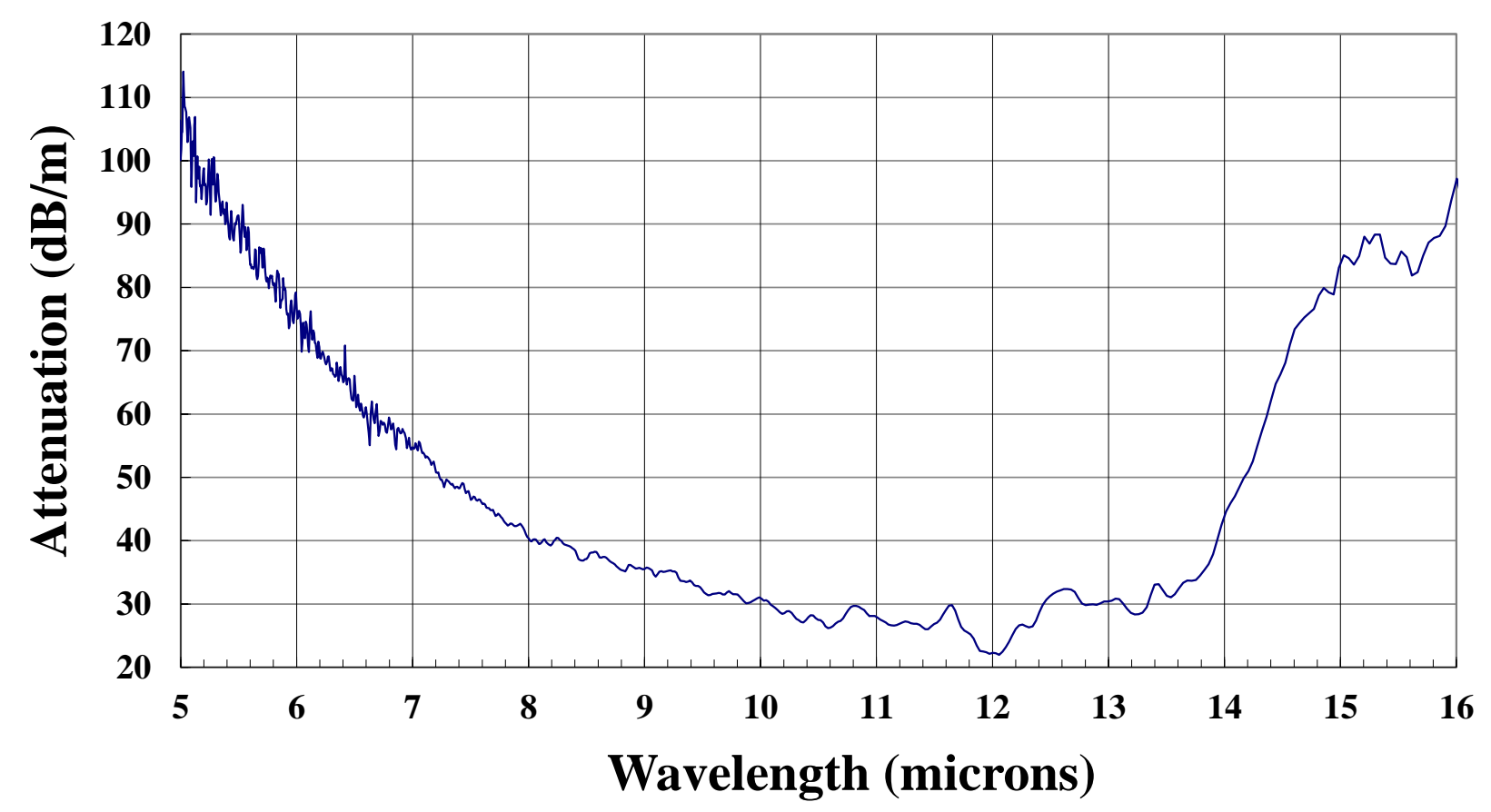

While the substitution of gallium for iodine is beneficial for optical losses, the presence of a volatile species in the reaction mixture poses a significant practical problem during synthesis. Indeed the high vapor pressure of iodine makes it very challenging to control the stoichiometry during purification and distillation as it tends to be pumped out of the reaction chamber. This leads to large variations in compositions that are problematic due to significant changes in physical properties of the glass with only a few percent off stoichiometry. Iodine-free glasses are therefore desirable.

\subsection{Tellurium Germanium Selenide Fibers}

In order to remove iodine from the glass composition, alternative additives with low coordination and good glass-forming tendency are wanted. As previously mentioned, elemental tellurium does not 
form glass but its group-VI neighbor, selenium, is a good glass-former in the elemental form or in combination with germanium. For example $\mathrm{GeSe}_{4}$ glasses do not exhibit any crystallization tendency at all. Tellurium and selenium are both divalent hence partial substitution of tellurium by selenium should be easily achievable and could lead to significant improvement of the glass stability against crystallization. Indeed it is shown that addition of selenium widens the glass-formation domain and increases the $\Delta T$ value up to $123{ }^{\circ} \mathrm{C}$ [18]. These glass compositions should therefore be good candidates for fiber production. In addition, it is well known that selenide glasses have lower band-gap than telluride glasses hence addition of selenium should significantly reduce the charge carrier absorption by raising the band-gap energy [29].

However, while selenium addition appears to be very beneficial for fiber production it should also be noted that the lower mass of selenium atoms should lead to higher phonon energies and may consequently reduce the infrared optical cut-off.

Figure 3 shows the attenuation curve of a $\mathrm{Ge}_{21} \mathrm{Te}_{76} \mathrm{Se}_{3}$ glass with a $\Delta T=123{ }^{\circ} \mathrm{C}$. The minimum attenuations are as low as $7 \mathrm{~dB} / \mathrm{m}$ in the 10-11 microns region. Another significant feature is that the optical cut-off has shifted from about 14 to 12 microns as expected from the higher phonon energy of selenium. The low background absorption also indicates that these glasses have a much lower population of free carriers due to the reduction in band-gap energy brought about by selenium addition.

Figure 3. Attenuation curve of a $\mathrm{Ge}_{21} \mathrm{Te}_{76} \mathrm{Se}_{3}$ glass fiber showing minimum loss around 10-11 microns.

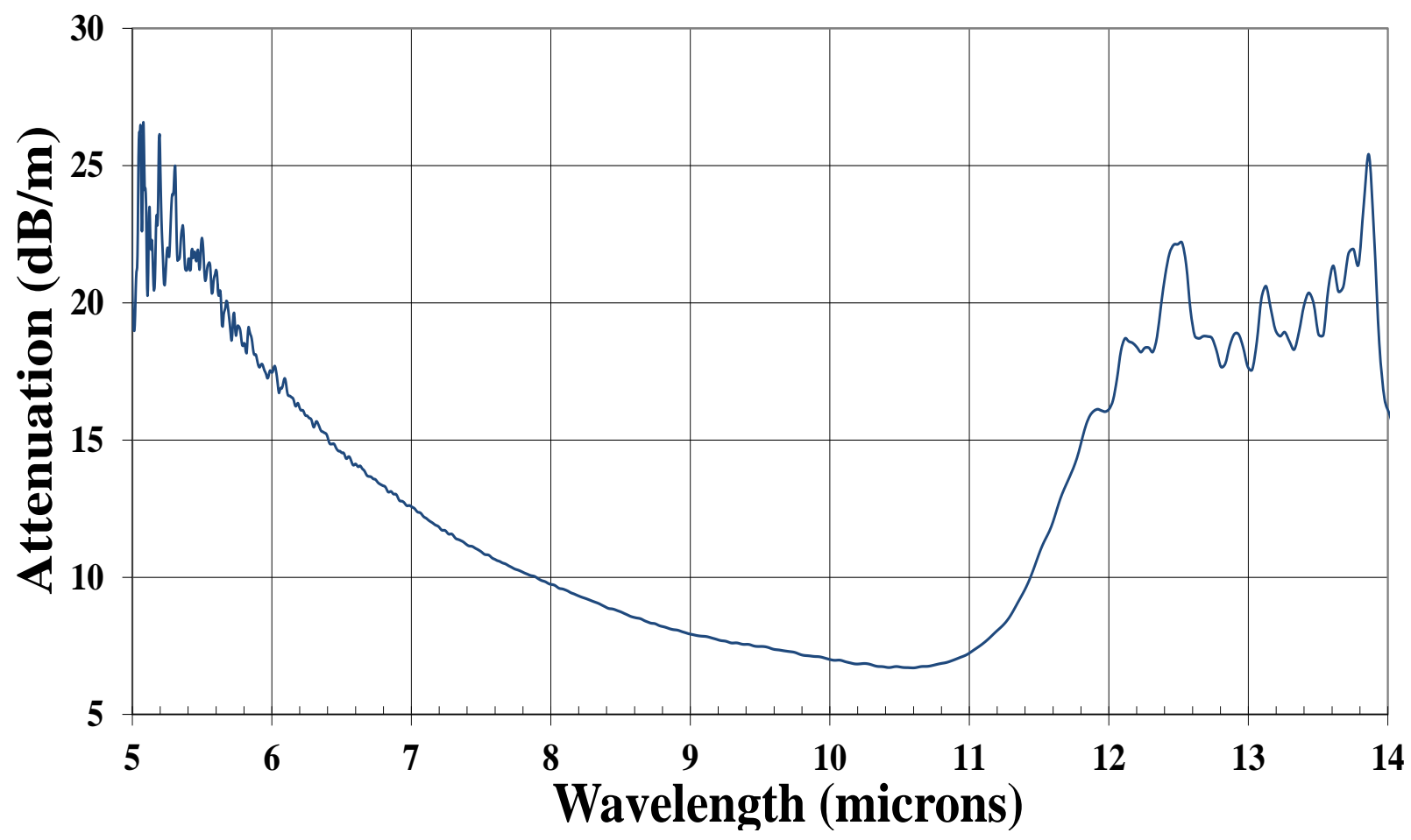

Overall the Ge-Te-Se glasses constitute the best compromise for the production of optical fibers with low-loss in the second atmospheric window at 8-12 microns. This range of wavelength is acceptable for many long wave applications such as laser surgery, thermal imaging or bio-sensing. Finally, the Ge-Te-Se compositions also lends themselves well to the production of double index fibers 
by simple substitution of selenium by tellurium to produce the necessary index contrast between the core and clad [19]. Single mode fibers at 10 microns should therefore also be possible.

\section{Conclusions}

It was shown that the composition of telluride glasses must be finely tuned to combine mutually exclusive properties such as low phonon energy for long infrared transmission and high band-gap energy for low free-carrier background absorption. While gallium provides high $T_{g}$ and wide optical window the impossibility of distilling gallium-containing glasses leads to unacceptable losses. Substitution of gallium by iodine permits the successful reduction of the background absorption but the high volatility of iodine leads to large compositional variation during vacuum synthesis. Overall, it is found that Ge-Te-Se compositions containing only a few percent of selenium constitute a good compromise between long-wave transmission and low background losses down to $7 \mathrm{~dB} / \mathrm{m}$.

\section{Acknowledgments}

This work was supported by the National Science Foundation under Grant Number ECCS-1201865, the CNRS International Associated Laboratory for Materials \& Optics and the Partner University Fund.

\section{Conflicts of Interest}

The authors declare no conflict of interest.

\section{References}

1. Lucas, P.; Riley, M.R.; Boussard-Pledel, C.; Bureau, B. Advances in chalcogenide fiber evanescent wave biochemical sensing. Anal. Biochem. 2006, 351, 1-10.

2. Riley, M.R.; Lucas, P.; Le, C.D.; Juncker, C.; Boesewetter, D.E.; Collier, J.L.; DeRosa, D.M.; Katterman, M.E.; Boussard-Pledel, C.; Bureau, B. Lung cell fiber evanescent wave spectroscopic biosensing of inhalation health hazards. Biotechnol. Bioeng. 2006, 95, 599-612.

3. Keirsse, J.; Lahaye, E.; Bouter, A.; Dupont, V.; Boussard-Pledel, C.; Bureau, B.; Adam, J.-L.; Monbet, V.; Sire, O. Mapping bacterial surface population physiology in real-time: Infrared spectroscopy of proteus mirabilis swarm colonies. Appl. Spectrosc. 2006, 60, 584-591.

4. Michel, K.; Bureau, B.; Boussard-Plédel, C.; Jouan, T.; Adama, J.L.; Staubmann, K.; Baumannc, T. Monitoring of pollutant in waste water by infrared spectroscopy using chalcogenide glass optical fibers. Sens. Actuat. B 2004, 101, 252-259.

5. Michel, K.; Bureau, B.; Pouvreau, C.; Sangleboeuf, J.C.; Boussard-Pl edel, C.; Jouan, T.; Rouxel, T.; Adam, J.-L.; Staubmann, K.; Steinner, H.; et al. Development of a chalcogenide glass fiber device for in situ pollutant detection. J. Non-Cryst. Sol. 2003, 326, 434.

6. Charpentier, F.; Bureau, B.; Troles, J.; Boussard-Pledel, C.; Michel-Le Pierres, K.; Smektala, F.; Adam, J.-L. Infrared monitoring of underground $\mathrm{CO}_{2}$ storage using chalcogenide glass fibers. Opt. Mat. 2009, 31, 496-500. 
7. Anne, M.L.; Le Lan, C.; Monbet, V.; Boussard-Pledel, C.; Ropert, M.; Sire, O.; Pouchard, M.; Jard, C.; Lucas, J.;. Adam, J.L.; et al. Fiber evanescent wave spectroscopy using the mid-infrared provides useful fingerprints for metabolic profiling in humans. J. Biomed. Opt. 2009, 14, 054033.

8. Hocde, S.; Loreal, O.; Sire, O.; Boussard-Pledel, C.; Bureau, B.; Turlin, B.; Keirsse, J.; Leroyer, P.; Lucas, J. Metabolic imaging of tissues by infrared fiber-optic spectroscopy: An efficient tool for medical diagnosis. J. Biomed. Opt. 2004, 9, 404-407.

9. Lavi, Y.; Millo, A.; Katzir, A. Flexible ordered bundles of infrared transmitting silver-halide fibers: Design, fabrication, and optical measurements. Appl. Opt. 2006, 45, 5808-5814.

10. Lavi, Y.; Millo, A.; Katzir, A. Thin ordered bundles of infrared-transmitting silver halide fibers. Appl. Phys. Lett. 2005, 87, 241122.

11. Wilhelm, A.A.; Boussard-Pledel, C.; Coulombier, Q.; Lucas, J.; Bureau, B.; Lucas, P. Development of far-infrared-transmitting te based glasses suitable for carbon dioxide detection and space optics. Adv. Mater. 2007, 19, 3796-3800.

12. Houizot, P.; Boussard-Plédel, C.; Faber, A.J.; Cheng, L.K.; Bureau, B.; van Nijnatten, P.A.; Gielesen, W.L.M.; Carmo, J.P.d.; Lucas, J. Infrared single mode chalcogenide glass fiber for space. Opt. Express 2007, 15, 12529-12538.

13. Danto, S.; Houizot, P.; Boussard-Pledel, C.; Zhang, X.H.; Smektala, F.; Lucas, J. A famiy of far infrared transmitting glasses in the Ga-Ge-Te system for space optics. Adv. Funct. Mat. 2006, $16,1847$.

14. Yang, Z.; Lucas, P. Tellurium-based far-infrared transmitting glasses. J. Am. Ceram. Soc. 2009, 92, 2920-2923.

15. Bureau, B.; Zhang, X.H.; Smektala, F.; Adam, J.-L.; Troles, J.; Ma, H.-L.; Boussard-Pledel, C.; Lucas, J.; Lucas, P.; Le, C.D.; et al. Recent advances in chalcogenide glasses. J. Non-Cryst. Solids 2004, 345\&346, 276-283.

16. Lucas, J. Infrared glasses. Curr. Opin. Sol. State Mater. Sci. 1999, 4, 181-187.

17. Lucas, P.; Yang, Z.; Fah, M.K.; Luo, T.; Jiang, S.; Boussard-Pledel, C.; Anne, M.-L.; Bureau, B. Telluride glasses for far infrared photonic applications. Opt. Mater. Express 2013, 3, 1049.

18. Maurugeon, S.; Bureau, B.; Boussard-Plédel, C.; Faber, A.J.; Lucas, P.; Zhang, X.H.; Lucas, J. Selenium modified $\mathrm{GeTe}_{4}$ based glasses optical fibers for far-infrared sensing. Opt. Mat. 2011, 33, 660-663.

19. Maurugeon, S.; Bureau, B.; Boussard-Plédel, C.; Troles, J.; Faber, A.J.; Lucas, P.; Zhang, X.H.; Lucas, J. Telluride glass step index fiber for the far infrared. J. Lightwave Tech. 2010, 28, 3358-3363.

20. Yang, Z.; Luo, T.; Jiang, S.; Geng, J.; Lucas, P. Single-mode low-loss optical fibers for long-wave infrared transmission. Opt. Lett. 2010, 35, 3360-3362.

21. Conseil, C.; Shiryaev, V.S.; Cui, S.; Boussard-Pledel, C.; Troles, J.; Velmuzhov, A.P.; Potapov, A.M.; Suchkov, A.I.; Churbanov, M.F.; Bureau, B. Preparation of high purity Te-rich Ge-Te-Se fibers for 5-15 $\mu \mathrm{m}$ infrared range. J. Lightwave Technol. 2013, 31, 1703-1707.

22. Lucas, J.; Zhang, X.H. The tellurium halide glasses. J. Non-Cryst. Solids 1990, 125, 1.

23. Ma, H.L.; Zhang, X.H.; Lucas, J. "High Tg" tellurium selenium halide glasses. J. Non-Cryst. Solids 1991, 135, 49.

24. Zhang, X.H.; Ma, H.L.; Blanchetiere, C.; Lucas, J. Low loss optical fibres of the tellurium halide-based glasses, the tex glasses. J. Non-Cryst. Solids 1993, 161, 327. 
25. Bureau, B.; Boussard-Pledel, C.; Lucas, P.; Zhang, X.; Lucas, J. Forming glasses from Se and Te. Molecules 2009, 14, 4337-4350.

26. Zhang, X.; Bureau, B.; Lucas, P.; Boussard-Pledel, C.; Lucas, J. Glasses for seeing beyond visible. Chemistry 2008, 14, 432-442.

27. Martin, R.M.; Lucovsky, G.; Helliwell, K. Intermolecular bonding and lattice dynamics of selenium and tellurium. Phys. Rev. B 1976, 13, 1383-1395.

28. Golovchak, R.; Calvez, L.; Bureau, B.; Jain, H. Structural evolution of Ga-Ge-Te glasses by combined exafs and xps analysis. J. Chem. Phys. 2013, 139, 054508

29. Yang, Z.; Gulbiten, O.; Lucas, P.; Luo, T.; Jiang, S. Long-wave infrared-transmitting optical fibers. J. Am. Ceram. Soc. 2011, 94, 1761-1765.

30. Churbanov, M.F.; Shiryaev, V.S.; Smetanin, S.V.; Pimenov, V.G.; Zaitseva, E.A.; Kryukova, E.B.; Plotnichenko, V.G. Effect of oxygen impurity on the optical transmission of $\mathrm{As}_{2} \mathrm{Se}_{3.4}$ glass. Inorg. Mater. 2001, 37, 1188-1194.

31. Jovari, P.; Kaban, I.; Bureau, B.; Wilhelm, A.; Lucas, P.; Beuneu, B.; Zajac, D.A. Structure of Te-rich Te-Ge-X (X = I, Se, Ga) glasses. J. Phys.: Condens. Matter 2010, 22, 404207

32. Calvez, L.; Ma, H.L.; Lucas, J.; Zhang, X.H. Selenium-based glasses and glass ceramics transmitting light from the visible to the far-IR. Adv. Mat. 2007, 19, 129.

(C) 2013 by the authors; licensee MDPI, Basel, Switzerland. This article is an open access article distributed under the terms and conditions of the Creative Commons Attribution license (http://creativecommons.org/licenses/by/3.0/). 